\title{
VENGANZA Y REPRESIÓN DURANTE EL FRANQUISMO
}

\author{
Jesús J. Alonso Castroviejo*
}

\section{Planteamiento y fuentes.}

Adentrarse en el pasado es oficio de historiador. La elección del tema nunca es casual, señalaba, con evidente acierto, el maestro E. H. Carr ${ }^{1}$. Comprender los motivos que me han llevado a plantear este estudio explicarían una buena parte de la exposición y de las posibles conclusiones a las que llegue al final de estas líneas. Sin embargo confieso mi perplejidad inicial: no viví la Guerra Civil española ni los años en los que transcurre esta historia. Apenas llegué a ser consciente de lo que significaba el régimen de Franco. Mi curiosidad historiográfica hacia ese período ha sido más bien escasa hasta este momento. El grueso de mis investigaciones se han centrado en los orígenes y consolidación de la revolución liberal-burguesa..., algo bastante alejado de lo que aquí trato. Tampoco hay interés personal, pues mi familia sobrevivió, anónima a los dos bandos, a la tragedia. Pero bastaron unas insinuaciones de personas que habían conocido los hechos a través de la transmisión oral para que lo que ocurrió en Villamediana en 1952 se pudiera convertir en metáfora de la situación que sufrieron los pueblos del interior de España, donde verdugos y víctimas convivían diariamente y donde los primeros no dejaron de recordar nunca a los segundos quién había ganado la guerra. Intentar describir, siquiera pálidamente, la opresión constante, las condiciones de una vida siempre bajo sospecha, serán algunos de los objetivos de este trabajo. Explicar por qué los acontecimiento fueron de una determinada manera y no de otra, debe ser la aspiración última de todo historiador que se acerque al pasado con afán comprensivo, ajeno a las tendencias "narrativas" que intentan eludir su responsabilidad interpretativa.

Pero para que lo ocurrido en Villamediana, un pequeño pueblo a cinco kilómetros de la capital de provincia, Logroño, pueda servir como esa metáfora a la que antes se aludía, hay que evitar recrearse en lo que de más localistas pudieran tener los hechos

\footnotetext{
* Profesor de Historia Contemporánea. Universidad de La Rioja

1. Carr, E.H.: ¿Qué es la bistoria?. Barcelona, 1980. Con similares argumentos se manifiesta, desde una óptica marxista, Schaff, A.: Historia y Verdad. Barcelona, 1976.
} 
e intentar introducir claves interpretativas de carácter más general. Las teorizaciones sobre la violencia que se han realizado últimamente en nuestro país, el cincuentenario de la Guerra Civil fue una buena ocasión para ello, pueden ser un buen punto de partida.

Frente a las caracterizaciones más obvias de la violencia que tiene como resultado último la desaparición física de uno de los actores -enfrentamientos civiles ${ }^{2}$, guerras, terrorismo...- y que son las representaciones más estudiadas por ser las más extremas, en este trabajo nos interesa reflejar otras formas de violencia, más difuminadas, pero no por ello menos efectivas. Bien es verdad que de lo que se va a tratar es de un asesinato, así fue definido en el juicio, pero ese hecho no deja de ser una consecuencia de toda una serie de factores que lo hicieron inevitable. Esas causas, ideológicas, personales, sociales, son el objeto prioritario de nuestro análisis. Para ello algunos conceptos nos serán de suma utilidad. Julio Aróstegui ha investigado de forma encomiable este campo y suyos son algunos trabajos básicos y referenciales, que han permitido un acercamiento más riguroso al fenómeno de la violencia. En concreto, para lo que aquí nos ocupa, son muy interesantes sus reflexiones sobre la definición de la violencia, que se apoyan en la numerosísima bibliografía anglosajona sobre el tema. Una aproximación por él citada puede iniciar nuestro acotamiento del concepto. Me refiero al término "violencia civil interna" ${ }^{3}$, que pretende limitar el conflicto al seno de grupos sociales delimitados -amplios o particulares- y excluye el enfrentamiento entre sociedades distintas. Pero esa violencia civil interna va a estar continuamente alimentada durante el primer franquismo por la sistemática "represión". Y éste es concepto que merece una detenida reflexión. Reig Tapia comentaba que era un tema polémico por dos motivos, la memoria histórica y la cuantificación de las víctimas ${ }^{4}$. En este trabajo no se van a contabilizar víctimas, pues me voy a centrar en un sólo caso. Pero sí que me interesa el tema de la memoria, por lo que tiene de elaboración de la experiencia inmediata, base fundamental del conocimiento transmitido por los vencidos. Los escasos supervivientes hablaban, y aún hoy, de unas condiciones de vida lamentables, de una persecución obsesiva, de una libertad vigilada. Luis Romero en "El concepto de represión" decía que era un término que se quedaba corto, pues las represiones se interfieren y se producen oscuridades. Más adelante señalaba que "resulta desagradable adentrarse en los entresijos de la crueldad, las simas del odio cainita y el sadismo homicida"s. Una continuada represión nos hace llegar a esos extremos. Porque la represión es un concepto que debe abarcar más que las muertes de posguerra e introducir otro tipo de variables, como las señaladas por $\mathrm{H}$. Heine ${ }^{6}$ y que coinciden con la

2. Waldmann, P.:"Sociedades en guerra civil: dinámicas innatas de la violencia desatada" pp. 145-168 en Violencia y política. Sistema, números 132-133, 1996. p. 20 .

3. Aróstegui, J.:"Violencia, sociedad y política: la definición de la violencia" en Ayer 1994, número 13.

4. Reig Tapia,A.:"Metodología de la represión" en Aróstegui,J.(ed.) : Historia y Memoria de la Guerra Civil. Valladolid, 1988. Vol. I, pp. 295-302.

5. Romero, L.: "El concepto de represión" en Aróstegui, J. (ed.): Historia y memoria de la guerra civil. Valladolid, 1988. Vol. I, pag. 290. Vid. también, Casanova, J.: "El pasado Oculto". Madrid. 1992.

6. Entendemos que el término represión política, aplicado al sistema franquista, no puede limitarse a aquella acción que, efectuada con fines políticos, tenga por objetivo privarle al enemigo político de su vida, su libertad personal o de sus medios de subsistencia económica, ni que está circunscrito a la supresión de los derechos de asociación y reunión, sino que comprende también otras facetas, cuya finalidad política a primera vista no siempre resulta tan clara como en las categorías antes citadas, tales como la represión laboral y eco- 
definición que un teórico francés da de la violencia opresiva ${ }^{7}$, menos aparente, pero no menos real, y que es la establecida, la constante, la que impregna cada una de nuestras actividades diarias y que el grupo vencedor no deja de mantener para humillar aún más a los derrotados. La violencia es el resultado último del conflicto social, cuando éste no se ha podido solventar por los cauces legales previstos para ello -elecciones, parlamentarismo...-. Hoy nadie duda que la Guerra Civil española fue un claro exponente de este conflicto, en el que una de las partes, el bloque oligárquico agrario y financiero, viendo que estaba siendo derrotado en el plano político-democrático, optó por acudir a otros medios para imponer sus criterios. Si en 1824 los franceses impidieron a Fernando VII que fuese demasiado cruel en la represión de los liberales, en 1939 Europa comenzó una guerra que le impidió frenar el afán revanchista que el general Franco y los suyos impusieron para consolidar sus posiciones de poder.

Esa atmósfera es la que se vivió en la España interior durante los decenios centrales del siglo XX, con la simbología fascista presente en cada edificio y con el obsceno recuento de los años triunfales, más tarde trocados en años de "paz".

Las fuentes que se han utilizado han sido todas ellas de carácter oficial. Se ha evitado conscientemente el recurso a los recuerdos de algunos de los protagonistas por varios motivos. El primero de ellos porque el principal encausado y autor material de los hechos no ha sido localizado, a pesar de que pensamos que continúa vivo. Otros protagonistas han muerto y aunque algunos siguen residiendo en Villamediana y su acceso a ellos era relativamente sencillo, no se ha considerado oportuno, pues mantengo serias reservas hacia las fuentes orales como base estructurante del relato de los hechos. La crudeza de los acontecimientos, la dureza de la vida en aquella época, hace que, sin duda, la memoria se vuelva muy selectiva y los recuerdos de los protagonistas estén siempre tamizados por algo que pudo haber sido de otra manera. Desde luego no se está negando validez a los testimonios, no se quiere decir que las personas consultadas mientan, sino que su propia elaboración del pasado termina convirtiéndose en la "historia oficial".

Frente a ello no intento sacralizar el documento, todos sabemos que no es inocente, sino basar mi estudio en aquellas fuentes que se produjeron contemporáneas a los acontecimientos. El primer centro visitado fue el propio Ayuntamiento de Villamediana. Libros de defunciones de registro civil, Padrón de vecinos y el Libro de Actas del Concejo fueron los materiales consultados. Aunque cuantitativamente escasa, la información recogida permitió centrar el tema y diseñar las líneas de investigación.

La prensa provincial, sólo en Logroño había periódicos en esa época, apenas me sirvió de nada, pues la censura impuesta desde el Gobierno Civil no permitió que la opinión pública estuviera informada de lo que ocurría a media docena de kilómetros. Una escueta noticia del asesinato, una esquela del difunto y dos edictos oficiales, además de algunas noticias indirectas, fueron el escaso acopio realizado a partir del periódico La Rioja.

nómica, la cultural y la sexual" en "Tipología y características de la represión y violencia políticas durante el período 1939-1961" en Tusell, J. et al.: La oposición al Régimen de Franco. Madrid, 1990, pp. 309-324.

7. Lapierre, J.W.: "La violence dans les conflits sociaux" en La violence dans le monde actuel. París, 1968, pp. 133-134. Citado por González Calleja, E.:"Qué es y qué no es la violencia en política" en Violencia política i ruptura social a Espanya. 1936-1945. Revista Espai/Temps. Lérida, 1994, número 23, pp. 32. 
Los fondos de Gobierno Civil fueron el siguiente paso, pues desde sus dependencias se realizaron la mayor parte de las pesquisas y es donde se centralizaron, en un primer momento, todas las actuaciones. Sin embargo, el estado descriptivo de los fondos y la propia estructura administrativa de la institución no han hecho sencilla su consulta. Aún así se han conseguido algunas informaciones de gran valor.

Por último, los fondos judiciales, conservados en el Archivo Histórico Provincial de La Rioja, se convirtieron en la fuente principal del estudio. La sentencia, al ser pública pudo ser consultada sin dificultad. Sin embargo el sumario, sometido aún a la tutela administrativa y a los plazos de consulta señalados por la ley, era de imposible acceso -no debemos olvidar que los hechos ocurrieron en 1952 y la sentencia se dictó en 1956, por lo que aún no han transcurrido los cincuenta años que prescribe la ley, tanto la de patrimonio (16/85) como la de protección de la intimidad y el honor de las personas (2/82)-. Para poder consultarlo se solicitó permiso al Presidente de la Audiencia Provincial de Logroño, que lo concedió, atendiendo a su interés científico, bajo ciertos supuestos que afectan a la intimidad de las personas, por lo que durante todo el artículo se van a suprimir nombres propios o características identificativas de los protagonistas. El sumario suministró, huelga decirlo, toda la información necesaria para una correcta reconstrucción de los hechos. Si ello no se ha conseguido, el único culpable es, por supuesto, el que esto suscribe.

Quiero agradecer a José Luis Gómez Urdáñez, Catedrático de Historia Moderna de la Universidad de La Rioja, el que me facilitara las primeras noticias sobre este asunto. Y al agradecer a Gómez Urdáñez su participación, este reconocimiento se hace extensivo a D. Manuel Tuñón de Lara, que en una visita a La Rioja conoció los hechos y le interesaron sobre manera. Desgraciadamente no podrá leer estas líneas, pero al menos que sirvan de dedicatoria a su dilatada carrera, tanto como historiador, como ciudadano de una España libre y democrática.

\section{LOS HECHOS}

En la mañana del día quince de mayo de 1952 se celebraban en el Ayuntamiento los tradicionales festejos en honor de San Isidro labrador, patrono del campo, fiesta que se extendía por toda la península, remarcando el carácter agrario que aún tenía España en esas fechas. El acceso al local no era libre, sino que se había reservado para los afectos al régimen: falangistas, ayuntamiento, maestro, clero, Hermandad de Labradores, en fin las conocidas fuerzas vivas que controlaban las pequeñas poblaciones como Villamediana.

Un grupo de excluidos, encabezados por el protagonista de este trabajo, a quién llamaremos "Ignacio" y que tenía dieciocho años en aquel momento, intentaron entrar al local, golpeando con rabia la puerta, siendo detenidos por Esteban Santolaya Lapuente, alias "Cateto", labrador, veterano falangista, ex alcalde y ex jefe local del Movimiento, que se encaró con "Ignacio", llegando a pegarle en una ocasión, y profiriendo frases ofensivas y de cierto tono chulesco, según algunos testigos.

8. A(rchivo) H(istórico) P(rovincial) de La R(ioja), Sección A(udiencia) Pr(ovincial), Libro de sentencias de 1956 , sentencia 27 . Del relato realizado por los jueces como hechos probados en la citada sentencia es de donde se ha extraído la narración fundamental de los acontecimientos. 
Esta ofensa causó honda impresión en Ignacio que esperó armado con una navaja a que terminara la celebración para matar al Esteban. Sin embargo no pudo realizar sus intenciones pues se lo impidieron tanto su grupo de amigos como otras personas que también salían del local. El maestro, presente en la algarada y delegado local del Frente de Juventudes, declaró que Ignacio iba profiriendo amenazas muy graves:

"Tengo una herida grande desde hace mucho tiempo y me lo tenéis que pagar"

Otro de los testigos presenciales, Julián Bretón García, nombrado Alcalde de Villamediana a raíz de estos suceso testificó que oyó decir a Ignacio:

“... ya llegó el día de la venganza”"10

Sin embargo el incidente terminó sin que sucediera nada irreparable y la bronca se olvidó, a pesar de que los enfrentamientos entre ambos protagonistas fueran más o menos continuos, llegando Ignacio a declarar que Esteban Santolaya le hacía la vida imposible y le perseguía donde quiera que le veía. Los orígenes de esta enemistad los trataremos más adelante.

El día 16 era viernes y la gente volvió a las tareas cotidianas después de un día de fiesta. Ignacio era jornalero del campo y trabajaba fundamentalmente para un mediano propietario de la localidad, B.S.M., que adquirió un importante protagonismo en este proceso. Al ser Ignacio huérfano de padre, B.S.M. oficiaba de consejero y fue quién ayudó a la familia a salir adelante, pues su situación, después de la Guerra Civil era realmente precaria. Una hermana era obrera en Logroño y un hermano mayor trabajaba también como obrero en una fábrica de zapatillas y se ocupaba eventualmente como jornalero. Cuando el Juzgado fijó los embargos necesarios para hacer frente a las responsabilidades que se derivaran del juicio, a Ignacio sólo pudieron embargarle una finca de media hectárea y 410 pesetas, pues nada poseía.

El sábado día 17, sobre las cinco y media de la tarde, cuando Ignacio y Esteban Santolaya estaban trabajando en dos fincas lindantes, sitas en la parte derecha de la carretera de Villamediana a Alberite, el Ignacio que realizaba el trabajo aludido por orden de B.S.M., aprovechando la circunstancia de hallarse Esteban Santolaya situado de espaldas, se fue aproximando al mismo con todo sigilo sin que su presencia fuera advertida por el otro que, ajeno por completo a lo que iba a suceder, trabajaba descuidado en la labor de arar, yendo inclinado sobre las dos manceras que sujetaba con ambas manos, y una vez que Ignacio le tuvo a su alcance, sin pronunciar palabra alguna y de una manera súbita que no dio lugar ni tiempo a reacción de ninguna clase por parte de la víctima, le asestó por detrás un golpe con el azadón que llevaba, golpe que al alcanzar a Esteban Santolaya, le causó una herida en la cabeza que le produjo la muerte y le hizo caer a tierra donde quedó tendido a los pies de Ignacio, que, inmediatamente, volvió a golpearle tres veces con el mismo artefacto, causándole otras tantas heridas también en la cabeza, dos de ellas mortales de necesidad como la primera, retirándose acto seguido el agresor del lugar del hecho, por haber advertido la pre-

9. A.H.P. de La R. Secc. A.Pr. Sumario, Leg. 522.

10. Ibidem. 
sencia de algunas personas por las proximidades de la finca, donde quedó el cadáver de Esteban Santolaya ${ }^{11}$.

La noticia apenas si encontró eco en la prensa provincial. La férrea censura evitó que el espacio dedicado al hecho sobrepasara una pequeña columna interior, aunque ya adelantaba el nombre del asesino. Más amplitud recibió la necrológica, en la que se detallaba la presencia del Gobernador Civil en el entierro de Esteban Santolaya. El Gobernador dirigió unas palabras a los asistentes en un clima de exaltado patriotismo. Aún se recuerdan algunas frases como: "tranquilo camarada, descansa en paz, que nosotros te vengaremos" ${ }^{12}$. También fue una demostración de fuerza de Falange, como se desprende de las declaraciones de uno de los testigos:

"...que habían subido unos individuos de Falange a Villamediana, cree que con el ánimo de tomar venganza"13

La esquela, de gran tamaño, incluía la concesión de indulgencias por parte del Obispo de la diócesis. Como se ve la presencia de las autoridades provinciales remarca el protagonismo político que había tenido el difunto en los primeros momentos de la rebelión militar contra la República. Unos días después se publicó, como anuncio oficial del juzgado la foto de Ignacio, para que cualquier persona que lo reconociera pudiera denunciarlo a las autoridades, pues se encontraba huido. El día 28 de mayo La Rioja se hacía eco de la sustitución de Leoncio García Martínez, alcalde de Villamediana durante los hechos, por Julián Bretón García, nuevo primer mandatario municipal y sobre quién recayó la responsabilidad de encontrar al asesino y calmar la convivencia social del pueblo. Por último, el periódico recogió meses más tarde el "rumor", inmediatamente confirmado, de la captura del sospechoso en San Sebastián ${ }^{14}$.

Ignacio se mantuvo evadido de la justicia hasta el 14 de noviembre de ese mismo año. Las primeras horas fueron momentos de confusión. Una vez cometido el asesinato inició una escapada que le llevó a las lejanas Mendavia y Alcanadre, a ambos márgenes del Ebro y a unos 25 kilómetros de Villamediana. La huida la realizó a pie y pobremente vestido:

“...vestía al fugarse una camisa azul clara [...] calzoncillo corto blanco en buen uso, camiseta de verano, pantalón azul bombacho [...] va sin calcetines, alpargata azul con suela de goma del número 42 , va descubierto..." ${ }^{15}$

A los dos días de vagar sin rumbo volvió a las cercanías de su pueblo, donde unos jornaleros al ver el lamentable aspecto que presentaba después de las horas que había permanecido merodeando por los parajes aludidos, sin comer y someramente vestido,

11. A.H.P. de La R. Secc. A.Pr. Libro de sentencias de 1956, sentencia 27. El relato ha recogido casi literalmente el que se reproduce en la sentencia, con ligeras modificaciones de estilo. La defensa de Ignacio señaló en sus conclusiones que Esteban Santolaya insultó al precitado, llamándole "babieca", cuando pasó junto a su lado, y que esto le produjo una gran ofuscación, que había que añadir a los insultos y agresiones recibidas dos días antes. ( $\mathrm{Vol}$ I)

12. Hernández García, A.: La represión en La Rioja durante la Guerra Civil. Logroño 1984, p. 238

13. A.H.P. de La R., Secc. A.Pr. Sumario, leg. 522

14. Diario La Rioja, ejemplares de los días 18, 20, 22, 28 de mayo y 16 de noviembre de 1952.

15. A.H.P. de La R. sec. A.Pr. Sumario, leg. 522 
se compadecieron de él y le prestaron dinero y algo de ropa. Pero lo más importante es que uno de ellos sostuvo una conversación privada con Ignacio. Esa noche se trasladaba de nuevo a Villamediana donde iba a permanecer oculto hasta la última semana del mes de julio ${ }^{16}$.

Del relato de los hechos resulta sorprendente que a pesar de las pesquisas de la Guardia Civil, la Policía Secreta y la Brigada de Madrid de investigación criminal, debido a:

"... el interés que este crimen despertó en todas las autoridades provinciales, tanto civiles como del Movimiento, [...] dado el carácter político que se le atribuyó" ${ }^{17}$,

no se pudiera apresar a Ignacio en el pueblo, que entonces contaba con unos mil seiscientos habitantes y unas quinientas casas. La solidaridad de una buena parte de la población, la de los derrotados en la guerra, fue sin duda una de la causas de que no fuera apresado entonces. Esta solidaridad se refuerza si consideramos que quienes lo cobijaron no eran familiares directos suyos.

De su permanencia como "topo" durante esos dos largos meses en una casa que, según consta en el sumario, fue registrada al menos en dos ocasiones hay una serie de circunstancias que pueden ilustrar perfectamente como la mayoría del pueblo participó en su ocultamiento. Un joven de su misma edad fue a cortarle el pelo en varias ocasiones ${ }^{18}$. Su familia lo visitaba con asiduidad. Incluso se comenta aún hoy en día que alguna vez se le vio intercambiando tebeos con otros jóvenes en las calles del pueblo. Lo que si es cierto es que durante su estancia en Villamediana se fue preparando la manera de sacarlo de su escondite y que cruzara la frontera con Francia. Un vecino le ofreció su propia pistola, un colt en perfecto estado que conservaba oculto desde la Guerra Civil. Por este ofrecimiento el propietario del arma fue condenado a tres meses de arrestó mayor, pero no por encubrir a Ignacio y facilitar su huida, sino simplemente por tenencia ilícita de armas.

La mujer propietaria de la casa donde se cobijó Ignacio, viuda, fue procesada y después absuelta del delito de encubrimiento. Durante el juicio llegó a declarar que una vez conocidos los hechos no dejó salir a Ignacio de la casa porque si lo hacía "... lo matarían y que por eso lo retuvo" ${ }^{\prime \prime}$.

El viaje a San Sebastián, etapa previa a su paso a Francia, fue preparado tanto por su hermano como por otros dos conocidos. Para ello contactaron con un taxista de Logroño, C.B., que había sido amigo del padre de Ignacio. Para evitar posibles investigaciones, pues el taxista estaba fichado por la Dirección General de Seguridad ${ }^{20}$, se

16. Aquí parece haber una contradicción entre lo que se supone probado en la sentencia, la permanencia de Ignacio en Villamediana entre finales de mayo y finales de julio y una de sus numerosas declaraciones sumariales, en la que afirma que se ocultó en la casa a finales de junio. Parece un vagabundeo excesivo un mes, sin ropa ni alimentos. Aunque también es posible que previamente estuviera escondido en otra casa, quizás en la de B. S. M. y que ésto no llegara a ser conocido por las autoridades.

17.A(rchivo) M(unicipal) de V(illamediana). L(ibro) de A(ctas), 16 de noviembre de 1952.

18. El padre del ocasional peluquero fue fusilado en "La Barranca" el día 26 de noviembre de 1936. Hernández García,A.: op. cit., vol. I, pag. 231.

19. A.H.P. de La R. sec. A.Pr. Sumario leg. 522.

20. Los antecedentes son estos: entre 1922 y 1931 fue denunciado cinco veces por escándalos en prostíbulos. En marzo de 1931 atentó contra la Guardia Municipal. En el año 1941 insultó a la Policía Armada. 
recurrió a su yerno, persona menos comprometida políticamente. La noche del 26 de julio salieron hacia la casa de un familiar de uno de los que le había preparado la fuga. El vecino donostiarra, H.S., cobró por el ocultamiento.

La estancia de Ignacio en San Sebastián duró tres meses y medio.Al principio no salía de casa, pues estaba extremadamente débil. Conforme iba mejorando empezó a salir y a sentirse más seguro. Estuvo una temporada trabajando en el mercado, acarreando mercancías y por las tardes salía a jugar a los futbolines o a las salas de baile. Le solía acompañar el hijo de su encubridor, que había militado en la milicia anarquista durante la guerra y que como consecuencia de la misma había perdido un brazo y una pierna. Mientras Ignacio vivía con cierta tranquilidad, sus conocidos iniciaron las gestiones para que pudiera cruzar la frontera. Al menos tres personas distintas lo intentaron. Pero todas las gestiones resultaron infructuosas. Los motivos por los cuales no se pudo lograr el paso a Francia los ignoro. Hernández García, en el breve relato que realiza de los hechos dice que "el muchacho no se atreve a cruzar la frontera" ${ }^{21}$. No debe extrañarnos, las posibilidades de una larga huida con éxito, quizás Sudamérica, eran escasas y el futuro que le aguardaba en Francia si era capturado, negro. Una de las personas que intentaron ayudarle a cruzar la frontera lo describió así:

“...si pasa a Francia sin documentación, sería internado en un campo de concentración y deportado a Indochina, o bien repatriado a España" ${ }^{\prime 2}$.

La falta de apoyos sólidos por parte de las estructuras partidarias que podían haberle facilitado documentación falsa y un paso de la frontera seguro puede ser una explicación plausible del por qué terminó siendo detenido en San Sebastián. Su larga permanencia en esa ciudad frustró, al final, todos los apoyos que había recibido hasta entonces.

\section{LOS ORÍGENES}

Ha llegado el momento de preguntarnos por qué un chaval de dieciocho años, de personalidad frágil e inmadura, catalogado por las autoridades fascistas como de mala conducta con anterioridad al asesinato de Esteban Santolaya, y quizás por ello continuamente hostigado por el "Cateto", pudo cometer el crimen, estar durante dos días obsesionado con la venganza y ejecutarla cuando encontró una ocasión propicia para ello. No esperó a ser más mayor, o a tener unas mayores posibilidades de huida. En esos tres días de mayo todo se precipitó en su cabeza y todas las historias que había oído a sus familiares sobre la Guerra Civil estallaron, sintiéndolas dolorosamente próximas.

La Guerra Civil se encuentra, por supuesto, en el origen de los hechos que estoy narrando.Villamediana fue uno de los pueblos de La Rioja que más muertes sufrió en

\footnotetext{
También se le implicó en el mercado negro de patatas. Durante la República fue afiliado de Izquierda Republicana y en los meses previos a la sublevación hizo repetidos viajes a Eibar para traer armas. Estuvo encarcelado en la prisión de Alfaro los primeros meses de la guerra. A.H.P. de La R. Secc. A.Pr. Sumario, leg. 522.

21. Hernández García, A.: op. cit. pag. 238.

22. A.H.P. de La R., Secc. A.Pr. Sumario, leg. 522. No hay que olvidar que en 1952 Francia mantenía una costosa guerra en sus posesiones del sureste de Asia, hasta que en 1954 se firmó la paz.
} 
los primeros meses de la rebelión ${ }^{23}$. No resulta extraño que el otro pueblo que se acerca al porcentaje de desapariciones sea Treviana, un pequeño núcleo, cercano a Haro, de similares características socioeconómicas. Pueblos con una elevada concentración de la propiedad, altas tasas de jornalerismo y una extraordinaria penetración de los partidos obreros, tanto de identidad marxista como anarquista. Sin embargo resulta cuando menos curioso constatar que en otros pueblos donde se produjeron violentas insurrecciones en el año 1934, llegándose a declarar el "comunismo libertario", como Cenicero $^{24}$, Fuenmayor, Briones, San Vicente y San Asensio, no se produjera una represión tan salvaje como la de Villamediana o Treviana. Sin duda los conflictos interpersonales se tiñeron de "políticos" en estos dos municipios para poder acometer toda clase de abusos de poder bajo el manto del "Alzamiento".

Cuadro 1: Represión en La Rioja, 1936.

$\begin{array}{lrrr} & \text { Represión } & \text { Población } 1930 & \% \\ \text { Briones } & 41 & 1.926 & 2,13 \\ \text { Haro } & 60 & 8.046 & 0,75 \\ \text { San Asensio } & 40 & 2.185 & 1,83 \\ \text { Treviana } & 44 & 1.060 & 4,15 \\ \text { Sto. Domingo } & 44 & 4.655 & 0,95 \\ \text { Nájera } & 62 & 2.856 & 2,17 \\ \text { Lardero } & 40 & 1.207 & 3,31 \\ \text { Logroño } & 286 & 34.329 & 0,83 \\ \text { Villamediana } & 60 & 1.424 & 4,21 \\ \text { Arnedo } & 57 & 5.356 & 1,06 \\ \text { Calahorra } & 400 & 12.004 & 3,33 \\ \text { Pradejón } & 44 & 2.436 & 1,81 \\ \text { Aldeanueva } & 53 & 2.749 & 1,93 \\ \text { Alfaro } & 163 & 7.679 & 2,12 \\ \text { Cervera } & 65 & 6.906 & 0,94\end{array}$

Elaboración propia. Fuente: Rivero Noval, op. cit. de cifras extraídas de Hernández García, op. cit. Para la población de los municipios en 1930, AA.VV.: La Rioja y sus tierras. Logroño, 1982.

El gobierno del Ayuntamiento de Villamediana en las fechas de la rebelión militar estaba constituido por la coalición frentepopulista y encabezado por un alcalde de Izquierda Republicana, D.Angel García Benito, que fue uno de los primeros fusilados. Ante las noticias de la insurrección y el avance de los requetés hacia La Rioja, el Ayuntamiento acuerda entregar armas a la población para defenderse. Sin embargo los efectivos navarros toman el municipio el día veinte de julio a media tarde. Muchos de los defensores han huido ${ }^{25}$.

23. Los datos que se reflejan en el cuadro 1 son una buena muestra de lo que se dice. Una sistematización de las cifras de Hernández García, op. cit., se encuentra en Rivero Noval, M.C.: La ruptura de la paz civil. Represión en La Rioja, (1936-1939). Logroño, 1992. Tanto los datos de Villamediana como los de Haro, Alfaro, Calahorra y Cervera son aproximados.

24. Bermejo, Fco.: "Cenicero, de Villa a Ciudad" pp.594-608, en Gómez Urdáñez, J.L. (dir.): Cenicero Histórico. Transformaciones económicas y cambios sociales en una ciudad riojana. Logroño, 1987.

25. Hernández García, A.: op. cit. pp. 234-239. 
Las primeras actuaciones de los grupos militares que controlan la villa son sintomáticas de lo que va a suceder. Detienen a los militantes de los partidos de izquierda, saquean los archivos de las agrupaciones locales y comienzan a tener la colaboración de los falangistas locales, entre ellos Esteban Santolaya y Leoncio García. El día veintitrés de julio se realizan simulacros de fusilamientos masivos en el frontón, para terminar de amedrentar a la población y conseguir su sumisión más absoluta, quebrando cualquier posibilidad de resistencia a la nueva autoridad. Hernández García sostiene que una de las causas más inmediatas de la ferocidad de la represión fue el intento, por parte de los anarquistas, de quemar la Iglesia en los días previos a la sublevación y la personalidad del párroco de Villamediana, de carácter inquisitorial y retrógrado ${ }^{26}$.

No estoy en disposición de contradecir con rotundidad estas afirmaciones, aunque parece obvio que ligar el anticlericalismo a la represión es sólo una de las aproximaciones que se pueden realizar y que en las sacas de Villamediana se dieron otros factores de carácter personal y social que profundizaron y continuaron la violencia desatada por la sublevación.

Entre esas sesenta personas, aproximadamente, que murieron en los primeros meses del golpe de estado, transformado en enfrentamiento civil, se encontraba un "hombre desconocido; pelo castaño oscuro, americana pana rayada, jersey cerrado con cremallera, camisa blanca rayada, pantalón dril rayado, zapatillas con suela de goma, calcetines negros. Fallecido el 26 de noviembre de 1936, por heridas de arma de fuego; enterrado en la dehesa de barriguelo ${ }^{27}[\ldots]$ deja cuatro hijos"28. Este hombre desconocido era Francisco, padre de Ignacio, militante del Partido Comunista de España. Su madre participaba de la misma ideología, por cuya causa permaneció detenida algún tiempo al iniciarse la sublevación ${ }^{29}$. No se puede asegurar que Esteban Santolaya participara directamente en su fusilamiento, pero si que parece, por los datos de transmisión oral recogidos y por algunos testimonios documentales, que participó activamente en varias sacas, sobre todo en las realizadas en el fatídico mes de noviembre, cuando más fusilamientos se produjeron en Villamediana. Protagonizó, antes de la rebelión, algunos enfrentamientos con militantes de partidos obreros, llegando a sacar una pistola en una local de baile. También fue de los primeros falangistas locales que se unieron a las tropas requetés cuando éstas tomaron el municipio.

Ignacio sólo contaba con dos años cuando fusilaron a su padre, por lo que no podía tener una memoria particular de lo sucedido. Fueron sus familiares, y las familias de los otros paseados los que mantuvieron vivo el recuerdo y fueron creando en él las ganas de venganza. Las viudas de los fusilados acudieron durante muchos años a "La Barranca" para honrar a sus muertos, a pesar de la oposición, a veces violenta, de las fuerzas de seguridad del Estado. Porque la represión no terminó en Villamediana

26. Ibidem. pag. 235 .

27. La dehesa de barriguelo apenas es conocida entre la población riojana por ese nombre; mucho más famosa es su otra denominación: "La Barranca" en el término municipal de Lardero. En la actualidad, y después de que durante muchos años no se permitiera a los familiares de las víctimas cercar el paraje se ha construido un sencillo cementerio que recordará para siempre a los asesinados en la retaguardia.

28. Registro civil de Lardero, tomo 20, inscripción 219, en Hernández García, op. cit. pag. 231.

29. La Guardia Civil aseguró en los informes evacuados a la autoridad judicial que Francisco "por su significación política desapareció al iniciarse el mismo [El Glorioso Movimiento Nacional]"A.H.P. de La R. Secc. A.Pr. Sumario, leg. 522. 
con el fin de la Guerra Civil sino que en los siguientes años se produjeron nuevos enfrentamientos que seguían recordando a los dos bandos de la contienda.

Los hechos que voy a relatar a continuación no han sido directamente investigados por mí, sino que encontré algunas referencias muy poco concretas en las diligencias sumariales, sobre todo en las declaraciones de algunos de los presuntos implicados y en los informes de las autoridades. En la actualidad nadie los ha trabajado exhaustivamente, aunque hay referencias en el trabajo de Paloma Fernández Pancorbo $^{30}$.

A pesar de la durísima represión y vigilancia a la que eran sometidas todas aquellas personas con un pasado de simpatías republicanas, los maquis se reorganizaban una y otra vez en el interior de España. Entre 1944 y 1945 se formó en La Rioja un grupo del Partido Comunista, jerárquicamente vinculado a Zaragoza. Entre sus ocupaciones se encontraba la de imprimir los folletos informativos del Partido, que en Logroño recibían el nombre de "Lucha". La multicopista utilizada llegó a estar escondida en un ataud de la Casa de Pompas Fúnebres Pastrana ${ }^{31}$. Pues bien, este grupo cayó durante las redadas de los meses de verano de 1945. Al menos dos de los implicados eran vecinos de Villamediana: A. S., alias "el Papos" y B.S.M..A "el Papos" se le detuvo por emisión de hojas clandestinas subversivas, sufriendo prisión en Zaragoza.A B.S.M. se le encontró en una bodega de su propiedad la multicopista utilizada para la elaboración de los folletos. Huyó por tal motivo y estuvo fuera de Villemediana entre ocho y diez meses. El Alcalde de Villamediana en 1952 informó también que “... se sabe y es notorio que con anterioridad hubo reuniones clandestinas en su bodega" 32

Estas actividades del maquis no están directamente relacionadas con el asesinato de Esteban Santolaya, pero creo que ejemplifican perfectamente la situación política y social que vivía el municipio en estos años y cómo, a pesar de todo el aparato represor del fascismo franquista, se mantuvo la lucha contra la dictadura, aunque bien es verdad que con nulos resultados, salvo los de incrementar las tragedias familiares de quienes aún creían que era posible derrocar a Franco.

Algunos teóricos sociales, a la hora de definir la violencia la adjetivan como "estructural" y representan la postura que supone que la violencia tiene su base y origen en una amplia situación de opresión, injusticias y desigualdades, tanto de carácter económico como social. En definitiva, en una situación de dominación ${ }^{33}$. Este proemio sirve para introducir el siguiente aspecto de mi análisis: la distribución de la propiedad de la tierra en Villamediana y la estructura socioprofesional de su población.

La estructura de la propiedad agraria útil del término municipal de Villamediana muestra una notable desigualdad en su reparto. El Indice de Gini, sin ser exagerado, 0,64, sí expresa ese desequilibrio. Otro dato interesante es la elevada proporción de tierra sometida a explotación. El municipio se extiende sobre 2.055 hectáreas de tierra, de las que 1.527 se utilizan para uso agrario, lo que supone un elevadísimo $75 \%$

30. Fernández Pancorbo, P.: El maquis al norte del Ebro. Zaragoza, 1988. María Cristina Rivero también los trata en su tesis doctoral en curso.

31. Fernández Pancorbo, op. cit. pag. 98.

32. A.H.P. de La R. Secc. A.Pr. Sumario, leg. 522.

33. Aróstegui, J.:"Violencia, sociedad..." p. 25. 
del total posible. El casco urbano, los caminos y el cauce del río Iregua, además de algún lleco y el monte de las bodegas ocuparían el resto.

El límite para que una explotación agraria pueda servir para alimentar a una familia sin ningún tipo de trabajo complementario, se puede establecer en torno a las diez hectáreas $^{3 \dot{4}}$. Pues bien, sólo el 9,4\% de las explotaciones superan esa cifra aunque representan el $44 \%$ de la superficie útil. Mientras, el 90,6\% de las explotaciones, inferiores a las diez hectáreas, suponían nada más que la otra mitad de la extensión agraria. Sus propietarios debían, por lo tanto, buscar trabajos alternativos para completar unos salarios que al menos les permitieran la reproducción social.Aquí no se incluyen, por supuesto, los braceros y jornaleros que no disponían ni tan siquiera de una parcela para poder formar parte de la estadística.

Cuadro 2: Clasificacion de explotaciones por tamaño.Villamediana 1962

\begin{tabular}{lrrrrrr}
\multicolumn{5}{c}{ Explotaciones } & \multicolumn{3}{c}{ Superficie } \\
Segmentos & Num. & $\%$ & acum. & Has. & $\%$ & acum. \\
0 a 1 & 210 & 46,9 & 46,9 & 86,0 & 5,6 & 5,6 \\
1,01 a 2 & 57 & 12,7 & 59,6 & 74,0 & 4,8 & 10,5 \\
2 a 3 & 36 & 8,0 & 67,6 & 85,0 & 5,6 & 16,0 \\
3 a 4 & 13 & 2,9 & 70,5 & 43,0 & 2,8 & 18,9 \\
4 a 5 & 22 & 4,9 & 75,4 & 95,0 & 6,2 & 25,1 \\
5 a 10 & 68 & 15,2 & 90,6 & 473,0 & 31,0 & 56,1 \\
10 a 20 & 33 & 7,4 & 98,0 & 433,0 & 28,4 & 84,4 \\
20 a 30 & 6 & 1,3 & 99,3 & 135,0 & 8,8 & 93,3 \\
30 a 50 & 3 & 0,7 & 100,0 & 103,0 & 6,7 & 100,0 \\
TOTAL & 448 & & & 1.527 & & \\
INDICE DE GINI: 0,64 & & & & &
\end{tabular}

Elaboración propia. Fuente: Censo Agrario de 1962.Agradezco a Emilio Barco el que me haya facilitado, ya depurados, estos datos.

El otro indicador que puede completar la visión más estrictamente económica de Villamediana es la ocupación socioprofesional de sus habitantes. Para ello me baso en el Padrón de Vecinos de $1955^{35}$. Por sectores, el primario ocupaba al 54\% de la población activa. El secundario al 36\% y el terciario al $10 \%$ restante. Como puede apreciarse, a pesar de ser un Padrón de hace escasamente 40 años la agricultura era aún la

34. No hay que olvidar que en esta zona había importantes superficies de regadío, lo que incrementaba la productividad, sin necesidad de gastar demasiado en fertilizantes inorgánicos. Un ejemplo puede servir. B.S.M., el patrón de Ignacio, declaró tener cuando le embargaron 34 fincas con una extensión de 12 hectáreas, tanto a su nombre como al de su padre, fusilado con otros parientes en la finca Ygay, propiedad del Marqués de Murrieta, en septiembre de 1936. Aunque los últimos estudios realizados estiman que para esta zona el mínimo para una explotación viable son 20 hectáreas, Tío Saralegui, C.: La agricultura riojana ante el año 2000. Logroño, 1993. vol. III, pp. 59-73. No debe extrañar la disparidad, pues mientras en 1960 la agricultura española se orientaba fundamentalmente a abastecer los mercados nacionales, en 1990, con nuestra integración en la Unión Europea los objetivos del campo español han cambiado radicalmente.

35. A.M. de Villamediana. Padrón de Vecinos de 1955. 
ocupación predominante en el pueblo. Como jornaleros y braceros se cataloga a 68 personas, un $20 \%$ de la población agraria. Vaqueros, pastores y esquiladores, 18 en total, serían otras categorías socioprofesionales. Donde hay más dificultad es en la distinción que se realiza en el Padrón entre agricultores y labradores. Los primeros son 167 , casi la mitad del total, mientras que los segundos son 94 . Por algunas indicaciones indirectas se puede deducir que agricultor sería aquel que tiene suficiente extensión agraria para sobrevivir, mientras que el labrador necesitaría el arriendo o una segunda ocupación para completar su salario. La conclusión es que casi la mitad de los que se declaran como trabajadores de la tierra (jornaleros, braceros y labradores) no poseen, ien 1955 !, la suficiente cantidad como para no depender de nadie más.

El segundo grupo ocupacional por activos empleados es el que genéricamente se define como "obrero" (114 declaraciones). Son gente joven la mayoría, que se ocupaba en las fábricas de conservas (Trevijano), las bogedas (Franco Españolas, Murrieta), el textil (Quemada) y las zapatillas (Fernández). Estos jóvenes treinta años antes hubieran engrosado las filas del jornalerismo. Sin embargo, en 1955, a la primera huida del campo a la ciudad se une la circunstancia de que muchos de ellos, aunque hubieran querido trabajar la tierra no hubieran podido, pues al ser descendientes de represaliados, los nuevos propietarios no los contrataban ${ }^{36}$. Solo en algunos casos, como el de Ignacio con B.S.M., coincidía que el propietario era, además, de ideología izquierdista.

Otra aproximación, ésta de mayor carácter especulativo, se puede hacer a partir de los datos del padrón. Es la que se refiere a dividir, de forma muy grosera, pues la fuente no permite grandes refinamientos, los ocupados en dos únicos grupos: los que sólo pueden ofrecer su fuerza de trabajo y aquellos otros que tienen capacidades, fortuna, tierra... Los primeros serían 360 personas, casi la mitad del total ${ }^{37}$, que son 638 personas ocupadas. Una fractura profunda del tejido social de un pueblo.

\section{Las Pesquisas}

La labor encomendada a los Gobiernos Civiles en la consolidación del nuevo Estado franquista fue fundamental para hacer llegar a todos los rincones la depuración y represión de todo lo que recordara los pasados tiempos de la República ${ }^{38}$. El Gobernador Civil de la provincia de Logroño cuando sucedieron los hechos, Alberto Martín Gamero, estuvo en el cargo casi diez años, entre 1946 y 1956. Como Gobernador Civil era la máxima autoridad en todo lo referente a orden público y por ello quién dirigió las investigaciones sobre el asesinato de Esteban Santolaya, camarada de partido y como él "camisa vieja". Martín Gamero era abogado y notario y se alistó voluntario en la División Azul, esa fantasmagórica brigada que pretendía derrotar al

36. Es el caso de la familia que ocultó a Ignacio, que se declaran exclusivamente como obreros eventuales. Ni tan siquiera pudieron alcanzar un trabajo digno. Esto, desde luego, también se puede definir como represión.

37. Se incluyen fundamentalmente: obreros, jornaleros, braceros, peones de albañil, labradores, albañiles.... Se excluyen los empleados públicos, los militares, profesiones liberales, agricultores, comerciantes...

38. Ortiz Heras, M.: Violencia política en la II República y el primer franquismo. Madrid, 1996, pp. 437-440. Nicolás Marín, M.E.: Instituciones murcianas en el franquismo. 1939-1962. Murcia, 1982, pp. 455-464. Ambos destacan el carácter preferentemente represor de la institución durante los primeros años del franquismo. 
ogro comunista en su propio terreno ${ }^{39}$. En su discurso de toma de posesión del Gobierno Civil de Logroño, sin embargo, se mostró dialogante y conciliador:

“...todos debemos cooperar al restañamiento de las heridas sufridas por España como consecuencia de la guerra, curación lenta que no depende de nuestra exclusiva voluntad de españoles"

Muy alejado, como veremos, de la forma en la que planteó la investigación. Su cese le llegó en febrero de 1956, sólo unas semanas antes de que se hiciera pública la sentencia sobre el caso. Su nuevo destino fue la provincia de Pontevedra. Es evidente que no se puede establecer una relación de causalidad entre ambos hechos, pero la suavidad de la condena, veinticinco años y ninguna intencionalidad de carácter político, tuvo que contrariar a quién propuso en algún momento la pena de muerte.Además la tardanza en capturar a Ignacio, seis meses, tampoco dejaba bien parada su presunta eficacia.

Desde que se recibieron las primeras noticias del asesinato, las autoridades provinciales se empeñaron en dotarlo de un componente político que no tenía. Ya en las primeras declaraciones de las personas afectas al régimen se insinuaba la posibilidad de que el asesino hubiera sido inducido por alguien. Julián Bretón, nombrado alcalde a raíz de los sucesos declaró "que alguién le haya [a Ignacio] inducido a tomar venganza[...] pero no puede determinar a persona alguna que haya podido quizás inducirle". En similares términos se expresaba un hermano de la víctima:

“...Su hermano Esteban no intervino para nada en la muerte del padre del Ignacio, pero salió voluntario con motivo del Movimiento y cree que esto haya dado lugar a engendrar odio en el Ignacio y haya sido ésta la causa de la muerte, bien de iniciativa propia o por inducción de alguien que no puede precisar" ${ }^{\prime \prime 1}$ [subrayado J.J.A.C.]

Esta declaración fijaba perfectamente tanto los orígenes remotos de la venganza, como ya hemos visto, como las líneas de investigación que se iban a adoptar en un primer momento. También desde el juzgado se mantenía esa pista como la más segura, aventurando quienes podían estar tras Ignacio: "investiguese a dos criados de B.S.M.". Otro declarante fué más preciso en sus acusaciones. P. P. H., labrador, llegó a afirmar, sin ningún tipo de pruebas:

$$
\begin{aligned}
& \text { "...que sospecha que el Ignacio haya sido inducido a realizar la muerte por su } \\
& \text { patrono B.S.M." }{ }^{\text {क2 }}
\end{aligned}
$$

Las razones por las cuales el testigo llegó a esa conclusión se desconocen, pero la policía y la guardia civil era lo que querían escuchar y dieron el testimonio por bueno. La delación, la venganza personal estaban, sin duda, detrás de esa declaración ${ }^{43}$.

39. Tuñón de Lara, M.: España bajo la dictadura franquista. (1939-1975). Barcelona, 1980, pag. 180. También se hace eco de esta participación y de la propaganda que conllevó Ellwood, S.: Prietas las filas. Historia de Falange Española, 1933-1983. Barcelona, 1984, pag. 143

40. La Rioja, 6 de abril de 1946.

41. A.H.P. de La Rioja, Secc. A.Pr. Sumario, leg. 522.

42. Ibidem.

43. No hay que olvidar que B.S.M. era un mediano propietario y que si se le involucraba en los acontecimientos sus bienes serían embargados y sacados a subasta, en el mejor de los casos, o regalados por los "servicios prestados". 
Aunque motivos había para sospechar de él. Lo primero que hizo Ignacio una vez asesinado Esteban Santolaya fue acudir a la bodega de B.S.M. a relatarle lo ocurrido. Expresiones como "ya ha caído ése" o "que he matado al Cateto" ${ }^{44}$ fueron pronunciadas por el homicida antes de iniciar la fuga.

B.S.M. pertenecía a una familia represaliada durante la Guerra Civil. Su padre y un tío suyo fueron fusilados en el mes de septiembre de 1936, después de estar escondidos en la Sierra de Cameros durante casi todo el mes de agosto. Su madre había estado encarcelada y dos hermanas suyas se llamaban con nombres alegóricos. Ya se ha visto como estuvo implicado en la redada de 1945 y tuvo que escaparse para evitar ingresar en prisión. Por lo tanto era una persona sumamente marcada ideológicamente y casi con toda seguridad militaba en el Partido Comunista.

La noche del asesinato hubo una reunión en casa de B.S.M.. Dos criados suyos, C.A. y D.S., salieron de madrugada a regar una finca y no volvieron hasta el amanecer. Este hecho levantó sospechas de todo tipo, por lo intempestivo del horario empleado para las labores de riego. Tanto es así que el juez solicitó la comparecencia de peritos diestros en el oficio que certificaran la necesidad de las labores declaradas. Estos confirmaron que era habitual regar por la noche, pero que la finca estaba en tan malas condiciones, con casi todo el fruto ya perdido, que hubiera dado igual no regarla, por lo que no se explicaban la prisa del propietario por mandar la labor. A pesar de algunas contradicciones menores entre los dos criados estos mantuvieron durante todos los interrogatorios la misma versión, aunque deslizaron una respuesta que puso en mayores dificultades aún a B.S.M.:

“...El B.S.M. decía que había hecho bien en no entregarse [Ignacio] ya que si lo hacía se jugaba la juventud" ${ }^{\prime 5}$

Estas declaraciones eran todo la que necesitaba la Guardia Civil para incriminar a B.S.M. como inductor y cómplice, aunque nunca encontraron a Ignacio en ninguna de sus propiedades. A partir de entonces las amenazas de dejarlo en la calle y embargarle todos sus bienes fueron constantes. Después de una primera comparecencia ante el juez y ante el aumento del enfrentamiento en el pueblo, B.S.M. huyó para evitar que lo encarcelaran, pues ya había estado en prisión con anterioridad por motivo de su ideología.

Esta huida reafirmó en las autoridades la idea de que era culpable y ordenaron su búsqueda y captura con tanta urgencia como la desplegada para intentar capturar al verdadero asesino. Lo encontraron en Bilbao, a donde se envío inmediatamenete una brigadilla de la policía para devolverlo a Logroño. La sorpresa de B.S.M. fue no tanto la presencia policial, sino que vinieran acompañados por tres falangistas logroñeses. Estos solicitaron permiso para trasladarlo ellos a Logroño, a lo que B.S.M. se negó, pues tenía miedo de que durante el viaje le aplicarán la "ley de fugas". Así se lo comunicó a la policía que consintió en custodiarle durante todo el trayecto.

44. A.H.P. de La Rioja, Secc. A.Pr. Sumario, leg. 522.

45. Ibidem. 
Los temores de B.S.M., y de todas las personas que de una u otra forma habían mostrado cualquier tipo de inclinación izquierdista, no eran infundados, pues entre otras amenazas corrió por el pueblo la siguiente, según una declaración del propio B.S.M.:

“...por haber dicho en el pueblo un tal 'Capachines', según rumores, sin que él [B.S.M.] lo oyera directamente, que había que matar esta noche a cuarenta o cincuenta para vengar la muerte de Esteban" ${ }^{16}$

A pesar de lo exagerado de la amenaza los ánimos estaban muy exaltados y desde la derecha fascista se le acusaba directamente de la muerte del falangista, incluyendo en la acusación a todos los que como él eran de ideología marxista, o simplemente desafectos al nuevo régimen:"enseguida se oyeron rumores que el público decía que no había sido el Ignacio, sino el B.S.M. y otros como el B.S.M.”.

El Gobernador Civil, mientras tanto, no hacía nada para calmar el enfrentamiento civil, al contrario, sus actuaciones se encaminaban a provocar una nueva purga entre el pueblo, en el que el asesinato no sería sino una excelente excusa. Por su interés se reproduce íntegra una comunicación interna enviada por el Gobernador al alcalde de Villamediana:

"7 de Julio de 1952.

Sr. D. Julián Bretón García.Alcalde de VILLAMEDIANA

Mi querido amigo y camarada:

Te envío el adjunto impreso que podrá servirte de borrador para que tanto tú como aquellos otros camaradas de absoluta garantía que tú recomiendes, podáis solicitar licencia de uso de arma corta gratuita.

Cuando estén todas las instancias debidamente rellenas me las traerás en propia mano.

Un cordial saludo de tu buen amigo y camarada,

Alberto Martín Gamero" 47

Parece obvio que armar a una parte del pueblo no era la mejor formula para acabar con el recuerdo de la Guerra Civil, tal como el mismo Gobernador prometió en su discurso de toma de posesión.

La estrategia de las autoridades era intentar incriminar por todos los medios a las personas vinculadas con los movimientos de oposición, para poder realizara así una nueva purga de desafectos que consolidara aún más el régimen y mostrara a los tibios su verdadero poder. Bajo continuas coacciones y torturas, los testigos declaraban al final lo que la Guardia Civil quería oír para poder actuar, amparados en el manto de la legalidad, contra sus enemigos políticos.

Ya se ha visto como en la sentencia se considera probado que no hubo ningún apoyo partidario para que Ignacio pasara la frontera y que sólo unos pocos amigos fueron los que le ayudaron. Pues bien, durante la toma de testimonios se insistía una y otra vez en la supuesta colaboración de unos guerrilleros. Cuando se detuvo a Plácido, verdadero encubridor de Ignacio, y la persona que más le ayudó mientras se mantenía huido, se intentó relacionar a otras dos personas en las gestiones para cruzar la fonte-

46. Ibidem.

47. A.H.P. de La R., Secc. Gobierno Civil, leg. 88. 
ra, E. G. y A. S. De "el Papos" ya conocemos como fue detenido en 1945 por distribución de propaganda ilegal. E. G. también había estado en la carcel, condenado por rebelión en 1946 y por fraude en 1950 . Ambos delitos no pueden ocultar el hecho de que los verdaderos motivos fueran de carácter ideógico. Plácido llegó a denunciar a ambos:

"...que en distintas ocasiones ha oído en su casa expresar a la madre y hermana de Ignacio que estos [E.G. y A.S.] eran los encargados de gestionar la huida y que habían de venir en un coche unos guerrilleros, o denominación parecida, para llervárselo" ${ }^{48}$

Las delaciones, bajo fuertes presiones de la policía, continuaban, y E. G. intentó descargar todas las responsabilidades en "el Papos", acusándolo de que "estaba gestionando la salida por medio del Partido o palabra similar". "El Papos", por su parte, confesó que había escrito una carta a un conocido suyo que vivía en Burdeos, para ver si desde Francia se podía hacer algo. La contestación fue negativa. Ambos fueron procesados y pasaron una corta estancia en prisión por estos hechos, pero ambos fueron finalmente absueltos por el tribunal que concluyó:"habiéndose supuesto, sin que aparezca acreditado, que los dos últimos realizaron algunas gestiones encaminadas a lograr que Ignacio se marchara a Francia”"

A pesar de las fuertes presiones a que fueron sometidos los testigos, curiosamente casi todos ellos familiares o amigos de Ignacio y de militancia izquierdista, el Gobierno Civil tuvo que abandonar esa línea de investigación, pues estaba claro que el caso no podía avanzar por ahí. Un informe de la Guardia Civil confirmaba el fracaso de esta orientación de las pesquisas:

"...Si bien es cierto que en la mentada localidad existe creencia general de que dicho autor obrara inducido por alguna otra persona, y con marcada sospecha sobre su patrón B.S.M., no han podido ser concretadas de una manera categórica tales afirmaciones, por cuanto no existe persona alguna que las mantenga por escrito" 50

Aunque no se pudo encarcelar a todos los que tuvieron, por mínima que fuera, relación con el caso, es verdad que la política represora logró introducir más miedo entre la población, cuando ya el régimen franquista se abría timidamente hacia el mundo.

Mientras tanto desde el Ayuntamiento de Villamediana poca cosa se podía hacer. El alcalde, Leoncio García, fué fulminantemente destituido el día 23 de mayo y nombrado en su lugar Julián Bretón, de menor significación falangista ${ }^{51}$. El nuevo alcalde intentó, a pesar de unas primeras declaraciones poco afortunadas contra Ignacio y B.S.M., que la población no reviviera la división de 1936. Pero lo único efectivo que realmente realizó fue el iniciar las gestiones para la instalación de un cuartel de la Guardia Civil "toda vez que existen problemas político-sociales que aconsejan su pronta realización" ${ }^{52}$. El cuartel estuvo terminado en un par de años. Por otra parte, intentaba tran-

48. A.H.P. de la R., Secc. A.Pr. Sumario, leg. 522.

49. A.H.P, de La R., Secc. A.Pr. libro de Sentencias de 1956, sentencia 27.

50. A.H.P. de la R., Secc. A.Pr. Sumario, leg. 522.

51. No hay que olvidar que Leoncio García participó, junto a Esteban Santolaya Lapuente, en la articulación del nuevo poder durante los primeros meses de la guerra. Hernández García,A.: op. cit. pp. 221 y 237.

52. A.M. de Villamediana, libro de actas, sesión de 2 de noviembre de 1952. 
quilizar a los vecinos declarando que el crimen no era más que un delito común, tesis finalmente asumida por el tribunal que juzgó y condenó a Ignacio.

Sin embargo el pueblo tenía sus propias ideas. El posicionamiento de los habitantes no admitió ambigüedades y solo algunas personas se sintieron despreciadas por ambos bandos, como un jornalero, R. P., que ayudó a Ignacio dándole 200 pesetas y no denunció el hecho, a pesar de que él se consideraba a sí mismo de derechas. Esto le costó dos días de cárcel y ser procesado en el juicio. El testimonio de su patrón, hombre que militaba en Falange, le libró de una condena en firme.

Pero quién verdaderamente hizo que se dirigieran las pesquisas hacia Ignacio fue el único testigo ocular de los hechos, A. B., labrador, que estaba laborando en las cercanías el día de autos. Su declaración fue clave para la reconstrucción de los hechos. Desconozco con exactitud su militancia política y los motivos que le indujeron a declarar en contra de otra persona. Aunque hubo, al menos, una persona con su mismo apellido fusilado durante la guerra no se puede establecer ningún tipo de filiación con el testigo presencial. Parace obvio que si algún familiar suyo hubiera muerto, A. B. hubiera conservado sentimintos de venganza y odio hacia quienes podían haber sido los ejecutores. Sin embargo su plena colaboración con la policía y la guardia civil y la continúa reafirmación de su primera declaración fueron estrechando el cerco en torno al joven que golpeó hasta la muerte a un enemigo personal.

Bien distinta fué la actitud de la primera persona que llegó al pueblo para informar de lo sucedido. T. L. entró en Villamediana a lomos de la mula de Esteban Santolaya Lapuente. Iba diciendo a todo el que se encontraba por el camino que la propia mula había matado al "Cateto", al propinarle una coz en la cabeza. Como puede apreciarse una versión radicalmente distinta de lo declarado por A. B. y que de haberse mantenido por todos los testigos hubiera supuesto que todo quedara en un desafortunado accidente, de los que no faltaban en el campo español. Sin embargo, la inmediata ratificación del testigo ocular en sus primeras afirmaciones dejó en un simple error lo propagado porT. L., quizás con la intención de salvar a Ignacio. Porque tampoco en este caso se pueden establecer las verdaderas intenciones del joven mensajero al intentar encubrir al homicida. De sus declaraciones sumariales no puede extraerse ninguna conclusión en un sentido u otro. Las listas de fusilados tampoco nos sirven de mucho pues, por supuesto, también hay personas con su mismo apellido que fueron paseadas.

La muerte de Esteban fue causa de bandería desde el primer momento y no faltaron manifestaciones públicas de condena o satisfacción por lo ocurrido. De las primeras ya hemos visto las continuas amenazas proferidas contra todo el que estuviera significado políticamente como de izquierdas. Pero no faltaron quienes expresaron su satisfacción por lo sucedido en público, con evidente peligro para su integridad física. El cinco de julio M. G. R. manifestó ante diversas personas, a voces, "que habían matado a Esteban Santolaya Lapuente porque era un canalla y un mal hombre". Quién dijo estas cosas era hija de represaliado y su madre una de las mujeres que con

53. A.H.P. de La R., Secc. Gobierno Civil, leg. 88. Posiblemenete la verdadera manifestación de M.G.R. fuera "Cateto", pues raramente en los pueblos se nombraba a las personas por sus verdaderos nombres, utilizándose habitualmente el apodo. 
más firmeza acudía todos los años a "La Barranca" para recordar el holocausto riojano ${ }^{54}$. El tumulto pudo ser sofocado sin necesidad de intervención de la fuerza pública y sin daños personales para ninguno de los presentes.

La detención de Ignacio en San Sebastián supuso el final de las pesquisas y el inicio del descubrimiento de la verdad. Las primeras declaraciones se realizaron en el propio San Sebastián, a bordo de un barco, quizás para poder tirar por la borda al detenido si no confesaba. Las torturas fueron habituales y en Logroño lo interrogaron colgado por las manos sin llegar a tocar suelo. El joven no pudo aguantar y terminó denunciando a todos los que de una u otra forma le habían ayudado. Salvo a su patrón, a quién exculpó de cualquier tipo de colaboración o encubrimiento. El nueve de marzo de 1956, casi cuatro años después, se hacía pública la sentencia.

\section{La Sentencia}

Junto a Ignacio fueron encausados las siguientes personas, todas ellas por un mayor o menor grado de encubrimiento, y por colaborar en su fuga: R. P., H. R., C. B. "Plácido", S. B., F. R., M. M., E. B., E. G.,A. S. "el Papos", F. R., C. B. y H. S.

Los jueces consideraron probada la culpabilidad de Ignacio como autor material de los hechos. Sin embargo en su tipificación del delito olvidaron cualquier motivación política. Tampoco observaron premeditación en la acción, lo que libró al acusado de una condena mucho más severa. También se olvidaron de la presunta participacion del "Partido" en el auxilio al acusado, lo que terminó por despojar al juicio de cualquier matiz de carácter político. Más benignos fueron con los presuntos encubridores, pues sólo consideraron realmente culpables a dos: C. B. "Plácido", que mantuvo en su casa de Villamedia a Ignacio entre mayo y julio y H.S. que lo ocultó en San Sebastián entre agosto y noviembre. A C. B., taxista, y F. R. se les acusó de colaboración para la fuga. Los cuatro fueron condenados a seis años y un día de prisión, que casi ya habían cumplido antes del jucio, pues todos ellos llevaban encarcelados desde el año 1952. Los demás encausados, incluida la madre de Plácido, fueron absueltos, salvo E. B. a quién se le condenó por tenencia ilícita de armas. A Ignacio se le condenó a veinticinco años de cárcel. En 1962 se le concedió la libertad condicional. Fué nuevamente indultado en 1964.

\section{CONCLUSIONES}

Del relato de los acontecimientos realizado hasta aquí, hay tres cuestiones que creo merecen una reflexión final a modo de conclusiones. La primera de ellas es la fecha en que se cometió el asesinato.Trece años después del último parte de guerra, ese de "cautivo y desarmado el ejército rojo...", las duras condiciones de vida parece que aconsejaban una prudente actitud hacia los vencedores. Sin embargo el odio y la venganza seguían presentes en cada uno de los actos cotidianos y tanto desde el poder como desde la memoria de los vencidos se mantenían vivos los motivos del enfrentamiento. La sociedad española seguía estando dividida, fundamentalmente por la incapacidad de los vencedores de tender una mano a los vencidos para reconstruir una nación en paz.

54. La expresión holocausto es utilizada por Pradas Martínez, E.: 1936. Holocausto en La Rioja. Logroño, 1982. 
Pero, desde luego, eso era algo que el poder no deseaba, pues era avanzada contra el marxismo, y las potencias internacionales, una vez terminadas las secuelas de la guerra mundial se volvieron hacia el régimen de Franco para introducirlo, lentamente, en el concierto internacional. Porque para 1952 se había iniciado la incorporación de España a los principales foros internacionales y al año siguiente se firmaría el tratado con Estados Unidos que suponía el reconocimiento a nivel mundial de la España franquista.

Por eso la actitud del Gobernador Civil puede sorprender en un primer momento y no entender como en una coyuntura internacional de apertura, cuando se estaba intentando dar una imagen "amable" del poder político, se pueda iniciar un movimiento represivo que intentaba amedrentar a la mitad de un pueblo. Pero es que ésa era la verdadera naturaleza del régimen, un orden que se basaba en la sistemática represión del enemigo político, con acciones que iban desde la eliminación física a la presión socioeconómica que hiciera insoportables las condiciones de vida. Porque el franquismo nunca dejó de utilizar la represión, ni tan siquiera cuando más consolidado estaba. No hay que olvidar que el general se despidió con cinco fusilamientos.Y es en actuaciones como la de Villamediana donde mejor se puede observar y experimentar esta realidad, donde el poder ejerce con absoluta impunidad sus políticas y donde cualquier acontecimiento es una buena excusa para iniciar medidas coercitivas que recuerden a la población quién es el que manda y para quién.

Mención aparte merece la actuación judicial. Si la justicia fue uno de los pilares de los primeros años del franquismo para legalizar los fusilamientos posteriores a la guerra, la actuación del tribunal que juzgó a Ignacio puede calificarse de benévola, pues aplicó las condenas mínimas que permitía el código penal en vigor. Su calificación de los hechos evitó penas más severas y un mayor número de condenados. Frente a los criterios del Gobierno Civil mantuvo el suceso como un delito común y obvió la presunta implicación de guerrilleros y partidos en la causa. Quizás porque los jueces eran civiles y no militares se pudo producir este fallo.

Por último, el pueblo que durante unos meses revivió el fantasma del enfrentamiento. La venganza de Ignacio sacudió las conciencias y requirió un posicionamiento moral a favor o en contra. Si durante seis meses se pudo mantener huido fue gracias a la colaboración de sus vecinos, que sin importarles las consecuencias de sus actos le encubrieron e intentaron su exilio. Le ayudaron incluso aportando el escaso dinero del que disponían. No debe extrañarnos que quienes más le apoyaron fueran hijos de paseados, jornaleros del campo de pocos recursos, obreros industriales de pobre salario. Gente con antecedentes que había conocido la cárcel franquista. Los vencidos, los derrotados, los humillados. Pero frente a este comportamiento está el de quienes lo delataron, aquellos que colaboraron con la polícia y la guardia civil y no tuvieron ningún problema en testificar hechos falsos si eso les permitía volver a encarcelar a sus enemigos. Porque por debajo de las presuntas motivaciones políticas fluye el odio cainita, el enfrentamiento personal entre familias que durante generaciones han estado pleiteando por motivos diversos. Una división de carácter social y económico que el franquismo no hizo sino agrandar, facilitando el que las desigualdades sociales crecieran, basadas en la imposición y la coerción de un aparato destinado a perpetuar una visión del Estado de corte patrimonial, ajeno a cualquier idea de reconciliación. Frente a ello el pueblo mantuvo su compromiso cívico de no olvidar nunca. Porque se puede llegar a perdonar, pero nunca debemos olvidar y labor del historiador es recordar a las futuras generaciones los hechos que les acontecieron a sus antepasados. 


\section{BIBLIOGRAFÍA CITADA}

AA.VV., 1982

La Rioja y sus tierras. Logroño.

ARÓSTEGUI, J., 1994

"Violencia, sociedad y política: la definición de la violencia" en Ayer 1994, número 13.

BERMEJO, FCO., 1987

"Cenicero, de Villa a Ciudad", en Gómez Urdáñez, J.L. (dir.): Cenicero Histórico. Transformaciones económicas y cambios sociales en una ciudad riojana. Logroño.

CARR, E. H., 1980

¿Qué es la historia? Barcelona.

CASANOVA, J., 1992

El pasado oculto; Fascismo y violencia en Aragón, 1936-1939. Madrid.

ELLWOOD, S., 1984

Prietas las filas. Historia de Falange Española, 1933-1983. Barcelona.

FERNÁNDEZ PANCORBO, P., 1988

El maquis al norte del Ebro. Zaragoza.

GONZÁLEZ CALLEJA, E., 1994

"Qué es y qué no es la violencia en política" en Violencia política $i$ ruptura social a Espanya. 1936-1945. Espai/Temps, número 23. Lérida.

HEINE, H., 1990

“Tipología y características de la represión y violencia políticas durante el período 1939-1961" en Tusell, J. et al. La oposición al Régimen de Franco. Madrid.

HERNÁNDEZ GARCÍA, A., 1984

La represión en La Rioja durante la Guerra Civil. Logroño.

LAPIERRE, J.W., 1968

"La violence dans les conflits sociaux" en La violence dans le monde actuel. París.

NICOLÁS MARÍN, M. E., 1982

Instituciones murcianas en el franquismo. 1939-1962. Murcia.

ORTIZ HERAS, M., 1996

Violencia política en la II República y el primer franquismo. Madrid.

PRADAS MARTÍNEZ, E., 1982

1936. Holocausto en La Rioja. Logroño.

REIG TAPIA, A., 1988

“Metodología de la represión” en Aróstegui, J. (ed.): Historia y Memoria de la Guerra Civil. Valladolid.

RIVERO NOVAL, M. C., 1992

La ruptura de la paz civil. Represión en La Rioja, (1936-1939). Logroño. 
ROMERO, L., 1988

"El concepto de represión" en Aróstegui, J. (ed.): Historia y memoria de la Guerra Civil. Valladolid.

SCHAFF, A., 1976

Historia y Verdad. Barcelona.

TÍO SARALEGUI, C., 1993

La agricultura riojana ante el año 2000. Logroño.

TUÑóN DE LARA, M., 1980

España bajo la dictadura franquista. (1939-1975). Barcelona.

WALDMANN, P., 1996

"Sociedades en Guerra Civil: dinámicas innatas de la violencia desatada" en Violencia y política. Sistema, números 132-133. 